\title{
Sintesis Senyawa Dihidropirimidinon Melalui Reaksi Siklokondensasi Menggunakan Katalis Larutan Asam Jawa
}

\author{
Fachri Hakim ${ }^{*}$, Irfan Fitriadi², Supartono ${ }^{3}$ \\ ${ }^{1}$ Pendidikan Kimia Fakultas Sains dan Teknologi Universitas Islam Negeri Walisongo \\ 2Program Studi Pendidikan Kimia Program Pascasarjana Universitas Negeri Semarang, Indonesia \\ ${ }^{3}$ Program Studi Kimia FMIPA Universitas Negeri Semarang, Indonesia \\ *Email: fachrihakim@walisongo.ac.id
}

\begin{abstract}
Abstrak
Tujuan penelitian ini adalah untuk mensintesis senyawa dihidropirimidinon melalui reaksi siklokondensasi Biginelli menggunakan katalis larutan asam jawa. Senyawa dihidropirimidinon merupakan hasil reaksi siklokondensasi biginelli dari aldehid, etil asetoasetat, dan urea atau tiourea yang memiliki aktivitas biologis dan bersifat antimikroba. Reaksi ini merupakan reaksi kondensasi antara benzaldehid 6, 2-indanon 2 dan urea 7 dalam suasana asam Identifikasi senyawa dihidropirimidinon dilakukan dengan uji FT-IR dan uji GC-MS. Dari hasil penelitian sintesis senyawa dihidropirimidinon dengan katalis larutan asam jawa membuktikan bahwa larutan asam jawa dapat digunakan sebagai katalis sintesis senyawa dihidropirimidinon melalui reaksi siklokondensasi Biginelli. Sehingga dapat digunakan untuk mengatasi wabah penyakit infeksi.
\end{abstract}

Kata kunci : Siklokondensasi; Larutan Asam Jawa; Dihidropirimidinon

\section{Pendahuluan}

Infeksi merupakan penyakit yang masih umum diderita oleh masyarakat Indonesia, yang merupakan penyebab kematian ketiga terbesar di dunia. Banyak penemuan mikroba patogen yang resisten terhadap antimikroba tertentu sehingga upaya untuk mendapatkan senyawa antimikroba baru perlu dilakukan secara terus menerus. Selama ini, senyawa antimikroba diproduksi oleh berbagai mikroorganisme, binatang dan tumbuhan. Senyawa antimikroba yang diproduksi melalui sintesis organik hanya sebagian kecil saja (Supartono, 2011).

Penyediaan antimikroba merupakan salah satu perhatian utama pemerintah dalam hal kesehatan untuk mengatasi wabah penyakit infeksi. Pemakaian antimikroba yang tidak teratur terbukti menyebabkan timbulnya resistensi, hal ini menyebabkan banyak antimikroba yang digunakan tidak efektif untuk mengatasi penyakit infeksi (Anam, 2012). Oleh karena itu diperlukan suatu tindakan untuk melawan resistensi antibiotik. 
Penggunaan antimikroba baru merupakan salah satu alternatif yang ditawarkan (Suwandi, 1992).

Salah satu senyawa yang memiliki aktivitas biologis dan bersifat antimikroba adalah derivat dihidropirimidinon

(DHPM).

Senyawa dihidropirimidinon merupakan hasil reaksi siklokondensasi Biginelli dari aldehid, etil asetoasetat, dan urea atau tiourea. Senyawa dihidropirimidinon memiliki aktivitas biologis baik sebagai antimikroba maupun pengobatan seperti aktivitas antivirus, antimikroba, antitumor, antihipertensi, antikanker, dan antiperadangan (Supartono, 2011).

Motivasi untuk mengembangkan pembuatan senyawa dihidropirimidinon dengan katalis yang diharapkan lebih ramah lingkungan banyak dilakukan. Berbagai macam cara yang dilakukan untuk pembuatan senyawa dihidropirimidinon, namun kondisi optimum pembuatan senyawa ini belum diketahui dengan pasti. Pengembangan melalui variasi katalis telah banyak dilakukan, namun penggunaan katalis yang tidak sesuai, juga akan mencemari lingkungan. Salah satu variasi yang dilakukan dengan menggunakan katalis larutan asam jawa.

Katalis diketahui merupakan suatu substansi dalam jumlah yang relatif sedikit tetapi dapat mengakibatkan perubahan laju reaksi yang besar, katalis hanya mempercepat dicapainya suatu reaksi. Salah satu alternatif katalis yang dapat digunakan adalah katalis heterogen berupa larutan asam jawa yang memiliki sifat berupa kemampuan untuk meningkatkan selektivitas dan aktivitas, proses yang lebih bersih, serta mudah dipisahkan setelah produk terbentuk.

Reaksi ini dikatakan reaksi berkatalisis, yakni fasa cair sebagai katalisnya dan dalam reaksi hidrasi ini larutan asam jawa yang berperan sebagai fasa cair. Adanya proses adsorpsi reaktan pada situs aktif katalis padat ini akan melepaskan energi dalam bentuk panas sehingga akan mempermudah molekul reaktan melewati energi aktivasi (Utomo, 2007).
Tanaman asam jawa (Tamarindus indica L.) merupakan tanaman yang berasal dari daerah savana yang gersang di Afrika, yang termasuk famili Leguminosae. Hampir semua bagian tanaman asam dapat digunakan untuk berbagai keperluan. Daging buah asam jawa sangat populer, biasa dipergunakan dalam aneka bahan masakan atau bumbu di berbagai belahan dunia. Banyak bagian pohon asam yang dapat dijadikan bahan obat tradisional. Getah daun digunakan sebagai diuretik. Daun dilaporkan memiliki khasiat kholagogik, laksatif, dan bersama buahnya digunakan untuk kongesti hati, konstipasi dan hemoroid (William, 2006). Ekstrak daun asam jawa memperlihatkan penghambatan $\alpha$-amilase, sehingga kemungkinan dapat digunakan untuk pengobatan diabetes tipe-2 (Funke dan Melzig, 2006).

Beberapa tahun terakhir banyak metode yang dikembangkan dalam penelitian ini untuk memperbaiki dan mengembangkan hasilnya, misalnya adalah penggunaan katalis asam lewis dan asam protik dibawah refluks, kondisi bebas pelarut, dan menggunakan penyinaran gelombang mikro (Amini et al., 2006). Pada penelitian ini akan disintesis senyawa dihidropirimidinon melalui reaksi siklokondensasi Biginelli menggunakan katalis larutan asam jawa.

\section{Metode Penelitian}

Bahan

Bahan yang digunakan dalam penelitian diantaranya: Benzaldehid Etylacetoasetat, Urea, Larutan asam jawa, Etanol. 
Pembuatan katalis larutan asam jawa

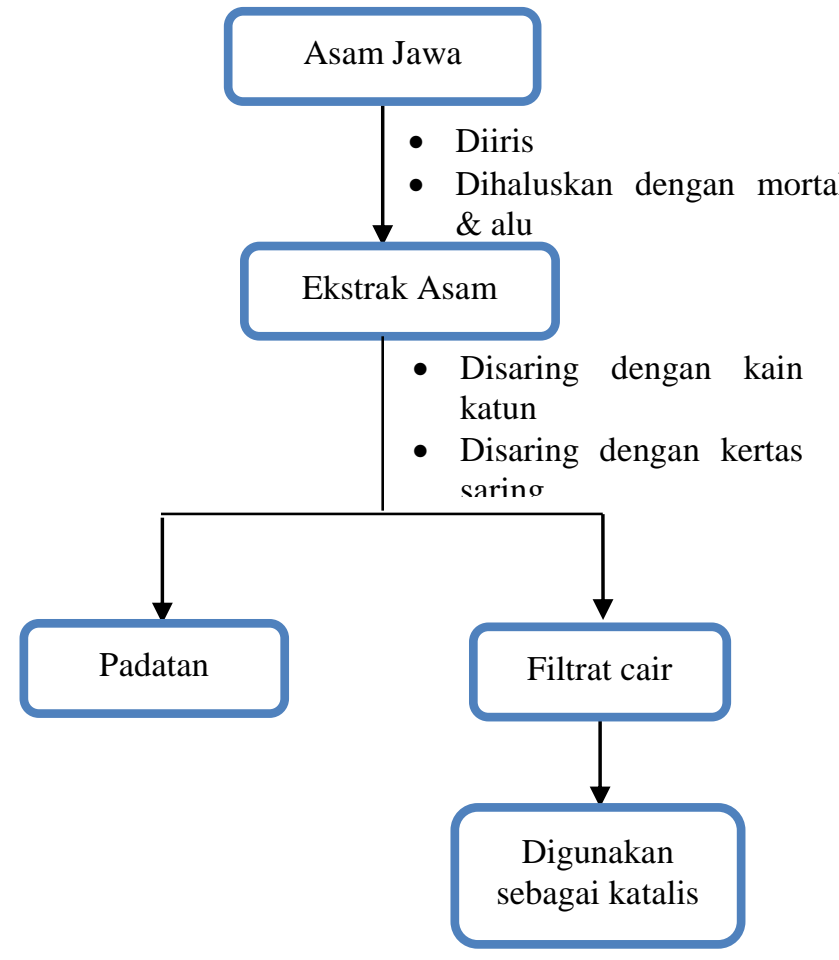

Selanjutnya, katalis larutan asam jawa $2 \mathrm{ml}$ yang sudah didapatkan kemudian dicampurkan $2 \mathrm{ml}$ benzaldehid, $2 \mathrm{ml}$ etil asetoasetat, dan 1,2 gram urea ke dalam tabung reaksi. Campuran tersebut kemudian dikocok selama 1 jam kemudian ditambah dengan 2 $\mathrm{ml}$ aquadest dan $2 \mathrm{ml}$ etanol. Setelah campuran homogen lalu dipanaskan selama 20 menit timbul 2 lapisan, kemudian didinginkan. Campuran tersebut kemudian disaring, sehingga terbentuk kristal pada kertas saring, yang selanjutnya nanti direkristalisasi dengan eter, dan disaring kembali sehingga didapatkan campuran Dihidropirimidinon murni.

\section{Karakterisasi Senyawa Dihidropirimidinon}

Kristal yang didapatkan dilakukan pengujian dengan IR yang bertujuan untuk menentukan gugus fungsi yang terkandung dalam suatu senyawa. Pengujian selanjutnya adalah uji kromatografi gas yang bertujuan untuk memisahkan komposisi sampel menjadi komponen-komponennya. Spektrum MS senyawa hasil sintesis diinterpretasikan dengan melihat ion molekul yang muncul sehingga dapat diketahui massa molekul (Mr), jumlah senyawa, konsentrasi senyawa dan rumus struktur senyawa hasil sintesis.

\section{Hasil Penelitian}

Percobaan ini menggunakan katalis larutan asam jawa muda pada reaksi Biginelli dengan pertimbangan bahwa penggunaan asam jawa muda sebagai katalis alami dalam reaksi Biginelli lebih berkhasiat dan optimal hasilnya daripada asam jawa matang/tua.

\section{Sifat Fisik}

Sintesis senyawa dihidropirimidinon, melalui reaksi siklokondensasi Biginelli dapat diidentifikasi berdasarkan sifat fisiknya. Dari hasil percobaan didapatkan senyawa yang mempunyai sifat fisik seperti ditunjukkan pada Tabel 1 .

Tabel 1. Hasil Sifat Fisik Senyawa yang Dihasilkan

\begin{tabular}{ccc}
\hline No & Sifat Fisik & Keterangan \\
\hline 1 & Wujud & Padatan \\
\hline 2 & Warna & Coklat \\
\hline 3 & Bau & Menyengat \\
\hline
\end{tabular}

Pengujian titik leleh dilakukan menggunakan Melthing point SMP-1. Senyawa dihidropirimidinon hasil reaksi sintesis dimasukkan dalam pipa kapiler, kemudian dimasukkan ke dalam alat. Pengamatan titik leleh dilakukan secara langsung pada saat senyawa mulai meleleh hingga meleleh semua. Hasil pengujian titik leleh disajikan dalam tabel berikut

Tabel 2. Interpretasi Titik Leleh Senyawa Dihidropirimidinon

\begin{tabular}{lll}
\hline No & Suhu & Titik leleh \\
\hline 1. & $40^{\circ} \mathrm{C}$ & $207^{\circ} \mathrm{C}$ \\
\hline 2. & $50^{\circ} \mathrm{C}$ & $207^{\circ} \mathrm{C}$ \\
\hline 3. & $60^{\circ} \mathrm{C}$ & $207^{\circ} \mathrm{C}$ \\
\hline
\end{tabular}


Analisis Senyawa Dihidropirimidinon dengan FTIR

Uji IR ini berfungsi untuk menentukan gugus fungsi senyawa hasil sintesis. Berdasarkan uji IR yang dilakukan, didapatkan puncak yang muncul pada bilangan gelombang seperti sebagai berikut

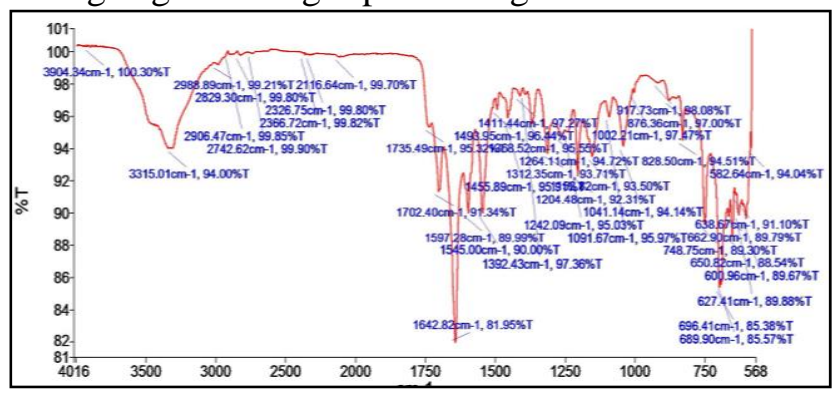

Gambar 1. Hasil Uji IR

Hasil interpretasi data spectrum IR senyawa dihiropirimidinon dalam bentuk tabel 3 berikut.

Tabel 3. Interpretasi spectrum IR dihiropirimidinon

\section{Gugus Fungsi Bilangan Gelombang}

\begin{tabular}{ll}
\hline $\mathrm{N}-\mathrm{H}$ (skunder) & $3315,01 \mathrm{~cm}^{-1}$ \\
\hline $\mathrm{C}-\mathrm{H}$ (alifatik) & $2988,89 \mathrm{~cm}^{-1}$ \\
\hline $\mathrm{C}=\mathrm{O}$ (karbonil) & $1702.4 \mathrm{~cm}^{-1}$ \\
\hline $\mathrm{C}=\mathrm{C}$ (alkena) & $1642,82 \mathrm{~cm}^{-1}$ \\
\hline $\mathrm{C}=\mathrm{C}$ (aromatik) & $1597,28 \mathrm{~cm}^{-1}$ \\
\hline $\mathrm{CH}_{2}$ & $1455,89 \mathrm{~cm}^{-1}$ \\
\hline $\mathrm{CH}_{3}$ & $1368,52 \mathrm{~cm}^{-1}$ \\
\hline $\mathrm{C}-\mathrm{O}$ (ester) & $1242,09 \mathrm{~cm}^{-1}$ \\
\hline
\end{tabular}

\section{Analisis Gc-Ms Senyawa Hasil Sintesis \\ Dihidropirimidinon}

Kromatografi adalah pengujian metode analisis yang bertujuan untuk memisahkan komposisi sampel menjadi komponen komponennya. Secara umum dasar analisis spektrometer massa adalah 48 menembak bahan yang dianalisis dengan berkas elektron dan secara kuantitatif mencatat hasilnya sebagai massa spektrum fragmen ion positif.

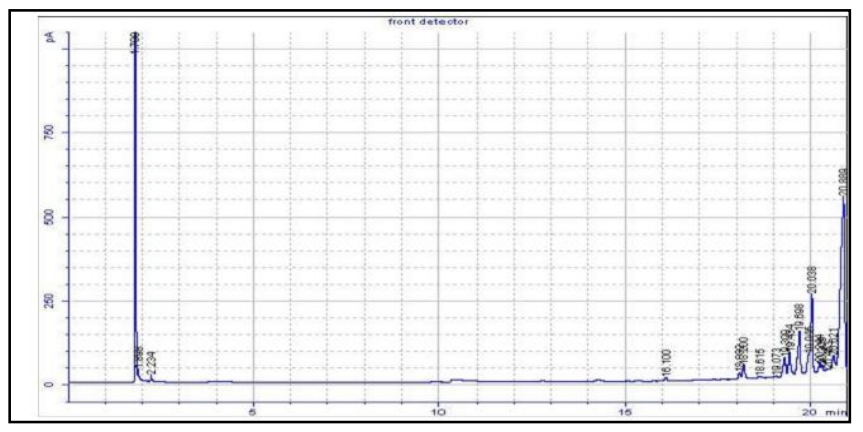

Gambar 2. Hasil Uji GC-MS

\section{Pembahasan}

\section{Sifat fisik dan kristal yang dihasilkan}

Pada sintesis dihidropirimidinon ini digunakan larutan asam jawa karena daging buah asam jawa mengandung $8-14 \%$ asam tartarat. Sintesis dihidropirimidinon ini digunakan benzaldehid, etil asetoasetat, urea dan katalis larutan asam jawa, setelah dikocok selama 1 jam campuran menjadi memadat. Hal ini menunjukkan larutan asam jawa dapat berfungsi sebagai katalis.

Kemudian campuran reaksi yang telah memadat lalu ditambah dengan $2 \mathrm{ml}$ aquadest dan 2 $\mathrm{ml}$ etanol diaduk kemudian dipanaskan selama 20 menit. Fungsi penambahan etanol adalah untuk melarutkan sedangkan pemanasan dilakukan bertujuan untuk mempermudah pelarutan senyawa dihidropirimidinon. Setelah disaring terbentuk kristal berwarna coklat. Pada percobaan yang kami lakukan dihasilkan kristal yang berwarna coklat sangat sedikit sehingga tidak dilakukan proses selanjutnya yaitu rekristalisasi dengan etanol yang diharapkan didapatkan kristal dihiropirimidinon yang telah murni yang berwarna putih.

Faktor-faktor yang menyebabkan kristal dihasilkan sangat sedikit kemungkinan adalah:

(a) Suhu yang digunakan pada pemanasan rendah mengakibatkan energi molekul yang dihasilkan 
kecil maka reaksi berjalan lambat sehingga belum terbentuk kristal secara maksimal.

(b) Pengocokan yang dilakukan kurang maksimal mengakibatkan frekuensi tumbukan antar molekul relative kecil sehingga reaksi pembentukan hidropirimidinon tidak berlangsung maksimal.

Semua senyawa hasil sintesis mulai meleleh pada suhu $207^{\circ} \mathrm{C}$. Beberapa referensi menyebutkan bahwa senyawa dihidropirimidinon memiliki titik leleh pada suhu antara $203-205^{\circ} \mathrm{C}$. Hal ini berbeda dengan hasil penelitian yang dilakukan yaitu sebesar $207^{\circ} \mathrm{C}$, ini dimungkinkan terjadi karena beberapa hal seperti kondisi reaksi yang berbeda, suhu dan tekanan yang berbeda, kondisi alat yang berbeda ataupun karena masih terdapat pengotor pada senyawa tersebut sehingga titik leleh yang dihasilkan tidak sesuai.

\section{Analisis senyawa dihidropirimidinon dengan FT- IR}

Analisis dengan spektrofotometer inframerah berfungsi untuk mengetahui struktur senyawa hasil sintesis. Gugus fungsi untuk bilangan gelombang spectrum inframerah dijelaskan pada tabel.4. Berdasarkan puncak-puncak serapan utama yang muncul, dapat diperkirakan bahwa hasil reaksi tersebut adalah dihidropirimidinon.

Hasil spektra yang diperoleh dapat diketahui adanya berbagai gugus fungsional yang terdapat pada senyawa hasil sintesis. Puncak yang terlihat pada bilangan gelombang $1667,2 \mathrm{~cm}^{-1}$ menunjukkan adanya gugus $\mathrm{C}=\mathrm{O}$. Terjadinya pergeseran serapan gugus $\mathrm{C}=\mathrm{O}$ ke arah bilangan gelombang yang pendek karena gugus $\mathrm{C}=\mathrm{O}$ berikatan dengan atom nitrogen yang memiliki satu pasang elektron bebas. Pasangan elektron bebas dari atom nitrogen ini dapat beresonansi sehingga mengakibatkan ikatan rangkap $\mathrm{C}=\mathrm{O}$ seolah-olah merupakan ikatan tunggal (karakter ikatan rangkap yang terjadi antara atom karbon dan oksigen akan berkurang) dan memperpanjang ikatan $\mathrm{C}=\mathrm{O}$.

\section{Analisis GC-MS senyawa hasil sintesis dihidropirimidinon}

Berdasarkan analisis dari GC-MS dapat diketahui kadar senyawa dihidropirimidinon yang dihasilkan pelarut sebesar $85,02 \%$, dengan waktu retensi 20,89 menit.

Analisis dengan GC-MS bertujuan mengetahui senyawa hasil reaksi siklokondensasi Biginelli dari etil asetoasetat, benzaldehid, dan urea menggunakan katalis asam jawa muda. Berdasarkan hasil kromatogram GC-MS dan spektrum massa senyawa hasil reaksi, dapat diperkirakan fragmentasi molekulnya.

Senyawa dihidropirimidinon mempunyai massa molekul m/z 260. Pada senyawa dihidropirimidinon dengan massa molekul 260 terjadi 2 pelepasan, yang pertama adalah lepasnya gugus benzil ditandai dengan munculnya pecahan 183 dan pelepasan $\mathrm{CH}_{3}$ ditandai dengan pecahan 245 .

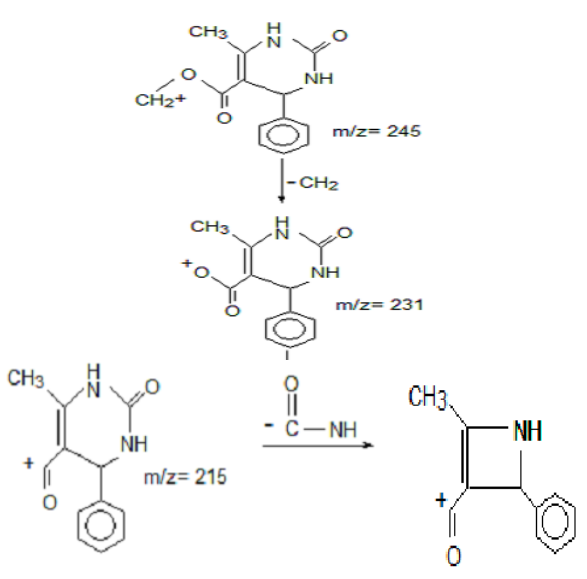

\section{Simpulan}

Berdasarkan hasil penelitian dan pembahasan yang telah diuraikan dapat disimpulkan bahwa asam jawa dapat digunakan sebagai katalis sintesis senyawa 
dihidropirimidinon melalui reaksi siklokondensasi Biginelli

\section{Daftar Pustaka}

Amini, M. M., A. Shaabani and A. Bazgir. 2006. Tangstophoosporic Acid (H3PW12040): An efficient Eco-friendly Catalyst for the Onepot Synthesis of Dihydropyrimidin-2-(1H)ones. Catalysis Communications 7: 843-847.

Atwal, K. S., Swanson, B. N., Unger, S. E., Floyd, D. M., Moreland, S., Hedberg, A., and O'Reilly, B. C. 1991, 3-Carbamoyl-4-aryl-1,2,3,4tetrahydro-6-methyl-5-

pyrimidinecarboxylic Acid Esters as Orally Effective Antihypertensive Agents. J. Med. Chem. 34, 806

Dolle, R. E., and Nelson, K. H., 1999, Comprehensive Survey of Combinatorial Library Synthesis J. Comb. Chem. 1, 235

Domling, A., 2002, Curr. Opin. Chem. Biol. 6, 306, cit., Bose, D. S., Sudharshan, M., Chavhan, S.W., 2005, New Protocol for Biginelli Reaction-a Practical Synthesis of Monastrol, Arkivoc, 3, 587

Funke I and MF Melzig, 2006.Traditionally used plants in diabetes therapyphytotherapeutics as inhibitors of a-amylase activity. Braz J Pharmacogn, 16(1): 1-5

Gordon, E. M., Gallop, M. A., and Patel, D. V., 1996, Strategy and Tactics in Combinatorial Organic Synthesis. Applications to Drug Discovery, Acc. Chem. Ret. 29, 144.

Hurst, E. W., and Hull, R., 1961, J. Med. Pharm. Chem. 3, 215.

Jauk, B., Pernat, T., and Kappe, C. O., 2000, Design and Synthesis of a Conformationally Rigid Mimic ... Calcium Channel Modulator SQ32,926, Molecules 5, 227.

Kape, C. O., 1998, 4-Aryldihydropyrimidines via Biginelli Condensations: Aza Analogs of
Nifedipine-Type Calcium Channel Modulators, Molecules 3, 1.

Kappe, C. 0.,1993, 100 Years of The Biginelli Dihydropyrimidine Synthesis, Tetrahedron 49, 6937 Kappe, C. O., 2000, Recent Advances in the Biginelli Dihydropyrimidine Synthesis. New. Tricks From an Old Dog, Acc. Chem. Res. 33, 879.

Kato, T.: Jpn. Kokay Koho 59 190,974: (CA 102:132067), 1984.

Mayer, T. U., Kapoor, T. M., Haggarty, S. J., King, R. W., Schreiber, S. I., and Mitchison, T. J., 1999, Small Molecule Inhibitor of Mitotic Spindle Bipolarity Indetified in a Phenotype- Based Screen, Science 286, 971.

Patil, A. D., kumar, N. V., Kokke, W. C., Bean, M. F., Freyer, A. J., Debrossi, C., Mai, S., Truneh, Fraulkner, D. J., Carte, B., Breen, A. L., Hertzberg, R. P., Johnson, R. K., Westley, J. W., and Potts, B. C. M., 1995 Novel Alkaloids from the Sponge Batzella sp.: Inhibitors of HIV gp 120-human CD4 Binding, J. Org. Chem. 60, 1182.

Rovnyak, G. C., Atwal, K S., Hedberg, A., Kimball, S. D., Moreland, S., Gougoutas, J. Z., O'Reilly, C., Schwartz, J., and Malley, M. F., 1992, Basic 3Substituted-4-aryl-1,4- dihydropyrimidine5-carboxylic Acid Esters. Potent Antihypertensive Agents, J. Med. Chem. 35, 3254, 1992.

Russowsky, D., Lopes, F. A., Da Silva, V. S. S., Canto, K F. S., D'Oca, M. G. M., and Godoi, M. N., 2004, Multicomponent Biginelli's Synthesis of 3,4-dihydropyrimidin-2(1K)-ones Promoted by SnCR2H2O, J. Braz.. Chem. soc. 15,2

Thompson, L. A., and Ellman, J. A., 1996, Synthesis and Applications of Small Molecule Libraries, Chem. Rev. 96, 555.

Weber, L., 2002, Multicomponent Biginelli's synthesis of 3,4-dihydropyrimidin-2- $(/ \mathrm{H})$ ones promoted by SnCb.2H2O. Drug. Disc. Today 7, 143. 
William JT, 2006. Fruit for the future 1, Revised edition: Tamarind (Tamarindus indicaL.) Dalam: William JT, RW Smith N Haq \& Dunsiger (eds). International Center for Underutilised crops, University of Southampton, Southampton, 2-32 